\title{
A histological study on acrylamide and cadmium chloride altered chick embryonic liver
}

\author{
Dr. Thyaga Raju Kedam ${ }^{1}$, Ruxana Begum Sheik ${ }^{2}$, Malekar Meena Bai ${ }^{3}$, \\ SK HaseenaBhanu ${ }^{4}$ \\ ${ }^{1-4}$ (Department of Biochemistry, SVU, Tirupati, India)
}

\begin{abstract}
Histology is the study of the microscopic anatomy of cells and tissues. The present study was made on control and treated chick embryonic liver tissues using toxic compounds like acrylamide (AC) \& cadmium chloride (Cd), on the morphological modification of embryonic liver and hepatic cells. The metal ion, $\mathrm{Cd}$, had severe damaging effect on chick embryonic liver than $\mathrm{AC}$ and however our study has revealed that these two are causing damage to the embryos.
\end{abstract}

Keywords: Acrylamide, Cadmium chloride, Chick embryonic liver tissues

\section{Introduction}

It is obvious that any chemical insult could cause injury to cells in animal if it is consumed beyond the safe doses. Susceptibility to chemicals, exhibits variation among the tissues and cells. The extent of severity of tissue damage is a function of the concentration and potentiality of the toxic compound [1].

The cyto architectural changes produced during chemical toxicity can be identified by microscopic examinations of the tissues and also explains the extent of tissue specificity to the chemical action. So histology is the study of tissues and it gives the insight into the functioning of tissues and organs. It is the study of changes in cell environment which envisage the cell anatomy. These studies pave a way to understand the pathological conditions of the animal organs. Histological analysis gives a clear picture to understand how the drugs cause injury to the tissue. The histopathology refers to the microscopic examination of tissue in order to study the manifestations of disease. In the $11^{\text {th }}$ day old chick embryo, histological changes were studied in the liver after Acrylamide and Cadmium chloride treatment.

1.1. Acrylamide: Acrylamide (AC) is an $\alpha, \beta$-unsaturated carbonyl compound fig $1 \mathrm{~A}$ with a significantly high chemical activity. The International Agency for Research on Cancer (IARC) has classified acrylamide as "probably carcinogenic to humans" [2]. Acrylamide, a monomer, from which polyacrylamides are synthesized, shall be used in the treatment of water, cosmetics and paper packaging.

Acrylamide is largely oxidized in mice, rats and humans to glycidamide (GA) fig1 B by its oxidating agent Cyp p450 2EI [3]. In humans, at relatively low doses of acrylamide, glycidamide is formed at higher extent than in rats, because of the higher levels of CYP2EI. Both compounds, AC and GA, are detoxified by glutathione conjugation and to some extent glycidamide is detoxified by hydrolysis.

During detoxification acrylamide reacts rapidly with SH groups, and also with proteins SH groups and amino groups. The most important reaction of acrylamide with proteins is the adduction to hemoglobin (Hb), SH groups of proteins and the $\mathrm{NH}_{2}$ groups of the $\mathrm{N}$-terminal valines of cytoskeletal proteins and protamines [4,5].

Acrylamide is clearly a direct-acting clastogen in mammalian cells in which it induces at lower extent chromosomal aberrations, micronuclei, sister chromatid exchanges (SCE), polyploidy, aneuploidy and other mitotic disturbances in the absence of metabolic activation [6].

The standard bioassays conducted on rats by giving dissolved Acrylamide in drinking water, observed a number of benign and malignant tumors in a variety of sites (e.g. thyroid, adrenals, and testis). However, the clear cut genotoxicity of acrylamide in vivo in somatic and germ cells are able to form DNA adducts strongly suggest that a genotoxic mechanism for the carcinogenicity of Acrylamide.

1.2. Cadmium chloride: Cadmium, a non-essential transition heavy metal is commonly regarded as a pollutant of world wide concern. Cadmium and its salts have been widely used by lead, copper and zinc smelteries, alkaline accumulators, paint and 
plastic industries, causing increase in environmental contamination and water pollution. The use of Cadmium containing fertilizers, agricultural chemicals and pesticides might also contribute to contamination [7].

Cadmium is a potent human carcinogen and occupational exposure to it has been associated with cancers of lung, prostate, pancreas and kidney, because of its characteristics as a category I carcinogen (human carcinogen) by the IARC and the National Toxicology program of the USA $[8,9]$.

The classification of Cadmium as a human carcinogen is supported by strong evidence from animal experiments. In rodents, Cadmium induced tumors in various organs. Various Cadmium compounds have produced adenocarcinomas of the lung in rats after inhalation $[10,11]$. Tumors of prostate and pancreas were evoked by subcutaneous injection of Cadmium chloride in rats, tumors of the testis were induced by oral exposure and Cadmium produced local tumors at various sites of injection, typically sarcomas, in rats and mice [12].

Liver is one of the main target organs of environmental pollutants and xenobiotics. Thus the investigation on the capacity of these environmental pollutants to alter the activation and detoxication balance has great importance. The current study was designed to observe the effect of Acrylamide and Cadmium chloride in chick embryonic liver.

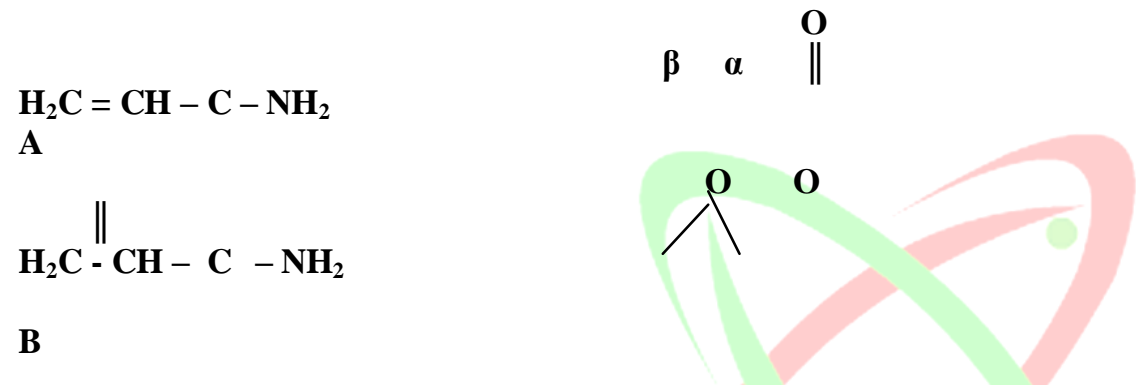

Fig. 1. Structure of A. Acrylamide and B. Glycidamide

\section{Materials and methods}

2.1. Source of Fertilized Eggs and Incubation Conditions: Freshly laid Bobcock strain zero day old fertilized eggs were purchased from Sri Venkateswara Veterinary University, Tirupati, Andhra Pradesh. They were incubated horizontally at $37.0 \pm 0.5^{\circ} \mathrm{C}$ with a relative humidity of $65 \%$ in an egg incubator, we considered day1 (d1) as an incubation period of $24 \mathrm{~h}$. The humidity of the incubator was maintained by keeping the tray full of water inside. The water was replaced every alternate day and the water level was maintained to keep the same percentage of humidity throughout the incubation. Eggs were rotated manually four times a day and were examined through the candler every day for the proper growth and viability. The dead eggs were removed immediately from the incubator. During all experiments, the embryos were maintained at $37.0 \pm 0.5^{\circ} \mathrm{C}$ except for brief intervals (60-120 seconds) required during the different treatment conditions. During this interval embryos experienced ambient room temperature $\left(29-30^{\circ} \mathrm{C}\right)$.

2.2. Acrylamide Treatment: A group of six eggs $(n=6)$ were maintained for each time point and dose. $0.1,0.2$ and 0.3 mg of Acrylamide in saline was administered as single dose separately to fertilized chick embryos on day8 (d8), day9 (9) and day10 (d10) of incubation.

2.3. Cadmium chloride Treatment: Cadmium chloride in saline in concentration of $0.01,0.02$ and 0.03 mg was administered as single dose separately to fertilized chick embryos on day 8 (d8), day 9 (d9) and day10 (d10) of incubation.

The egg shell was opened at the blunt end of the top to obtain access to the air cell, where the respective test substance (50 $\mu 1)$ was injected directly on to the inner shell membrane. Covering the hole by wax tape could ensure the embryos vitality for the remaining time until blood sampling and dissection. Chick embryonic liver was collected on d11 after 24hrs (d10), 48hrs (d9) \& $72 \mathrm{hrs} \mathrm{(d8)} \mathrm{initial} \mathrm{administration} \mathrm{of} \mathrm{the} \mathrm{test} \mathrm{substance.} \mathrm{The} \mathrm{tissue} \mathrm{was} \mathrm{washed} \mathrm{with} \mathrm{normal} \mathrm{saline} \mathrm{to} \mathrm{remove} \mathrm{blood} \mathrm{and}$ fat debris and stored at $-20^{\circ} \mathrm{C}$ until further use.

2.4. Fixation and staining of control and treated samples: The liver tissues were isolated from control and treated d11 chick embryos and were gently rinsed with physiological saline to remove blood and debris adhering to them. They were fixed in 
Bouin's solution until processing. This solution acts as a fixative for embryonic studies due to its excellent preservation of nuclei and chromosomes. The tissues were washed with running tap water, overnight to remove Bouin's solution. After dehydrating through a graded series of alcohols, the tissues were cleared in methyl benzoate and embedded in extremely hot liquid paraffin wax. Sections of liver were cut at $6 \mu$ thickness were stained with haematoxylin, a basic dye, stains nuclei blue due to an affinity to nucleic acids in the cell nucleus; eosin, an acidic dye, stains the cytoplasm pink. After dehydration and cleaning, sections were mounted in Canada balsam. Histological examinations of the tissues were followed according to Humason 1972 [13] and the specimens were observed under the light microscope.

\section{Results}

The results of control and treated chick embryo liver histology studies were presented in the fig 2 to 12 . In these results the control liver showed normal architectural hepatocytes showing clear nucleus and cytoplasm fig. 2 . The $0.1 \mathrm{mg}$ AC $(24,48$ \& $72 \mathrm{hr}$ ) treated liver showed early hepatic changes with mild granulation and vacuolating changes in the hepatocytes. Nucleus was pushed to the periphery of the cell fig. 3-5. The chick embryonic liver treated with $0.2 \mathrm{mg} \mathrm{AC} \mathrm{(24,} 48$ \& $72 \mathrm{hr})$ showed pycnotic nuclei i.e., nucleus of a cell undergoing programmed cell death or apoptosis due to irreversible condensation of chromatin. It was followed by fragmentation of the nucleus, sinusoidal hemorrhages, i.e., excessive discharge of blood from the blood vessels; profused bleeding and necrotic hepatocytes fig. 6 to 8 . Upon $0.3 \mathrm{mg} \mathrm{AC} \mathrm{(24} \mathrm{hr} \mathrm{and} 72 \mathrm{hr})$ treatment the chick embryonic liver hepatocytes showed more fatty changes, proliferation of sinusoidal spaces, hemorrhages, fatty infiltrations, necrosis i.e., the premature death of cells and living tissue, and complete loss of architectural details of the hepatocytes fig. $9,10.0 .3 \mathrm{mg}$ Acrylamide ( $48 \mathrm{hr}$ ) treated tissue showed similar histopathological changes as to that of $0.2 \mathrm{mg}$ Acrylamide (72 hr) treated tissue.

Cadmium chloride treatment with $0.01 \mathrm{mg}(24,48 \mathrm{hr})$ in chick embryonic liver showed similar changes as that of $0.2 \mathrm{mg}$ Acrylamide (48 hr) treated hepatocytes with mild vacuolations, and moderate degenerative changes of cytoplasm. Cadmium chloride treatment with $0.01 \mathrm{mg}(72 \mathrm{hr})$ in chick embryonic liver showed vacuolations in sinusoidal spaces fig $11.0 .02 \mathrm{mg}$ $\mathrm{CdCl}_{2}$ (24, 48 and $72 \mathrm{hr}$ ) treated liver showed hepatocytes revealing various necrotic changes, pycnotic nuclei and hemorrhages fig. 8, 9. $0.02 \mathrm{mg}$ Cadmium chloride (24 and $48 \mathrm{hrs}$ ) treated tissues showed similar changes as that of $0.2 \mathrm{mg}$ Acrylamide (72 hr) and $0.3 \mathrm{mg}$ Acrylamide (48 hr) treated tissues fig. 8. $0.02 \mathrm{mg} \mathrm{CdCl} 2(48 \mathrm{hr})$ treated tissue showed similar changes as that of $0.2 \mathrm{mg}$ Acrylamide $(72 \mathrm{hr}), 0.3 \mathrm{mg}$. Acrylamide $(48 \mathrm{hr})$ and $0.02 \mathrm{mg} \mathrm{CdCl} 2(24 \mathrm{hr})$ treated tissues fig. 8. $0.02 \mathrm{mg}$ of $\mathrm{CdCl}_{2}(72 \mathrm{hr})$ treated tissue showed similar changes as that of $0.2 \mathrm{mg}$ acrylamide treated tissue fig. $9.0 .03 \mathrm{mg}$ $\mathrm{CdCl}_{2}(24 \mathrm{hr})$ treated liver showed similar changes as that of $0.2 \mathrm{mg}$ Acrylamide $(48 \mathrm{hr}), 0.01 \mathrm{mg} \mathrm{CdCl} 2(24,48 \mathrm{hr})$ treated tissues fig. 7. $0.03 \mathrm{mg} \mathrm{CdCl}$ ( $48 \mathrm{hr}$ ) treated liver showed complete loss of architectural details of hepatic cells, pycnotic nuclei and complete necrosis fig $12.0 .03 \mathrm{mg}$ of $\mathrm{CdCl}_{2}(72 \mathrm{hr})$ treated tissue showed similar changes as that of $0.3 \mathrm{mg}$ Acrylamide (24 hr) and $0.02 \mathrm{mg}$ of $\mathrm{CdCl}_{2}(72 \mathrm{hr}$ ) treated tissues fig. 9.

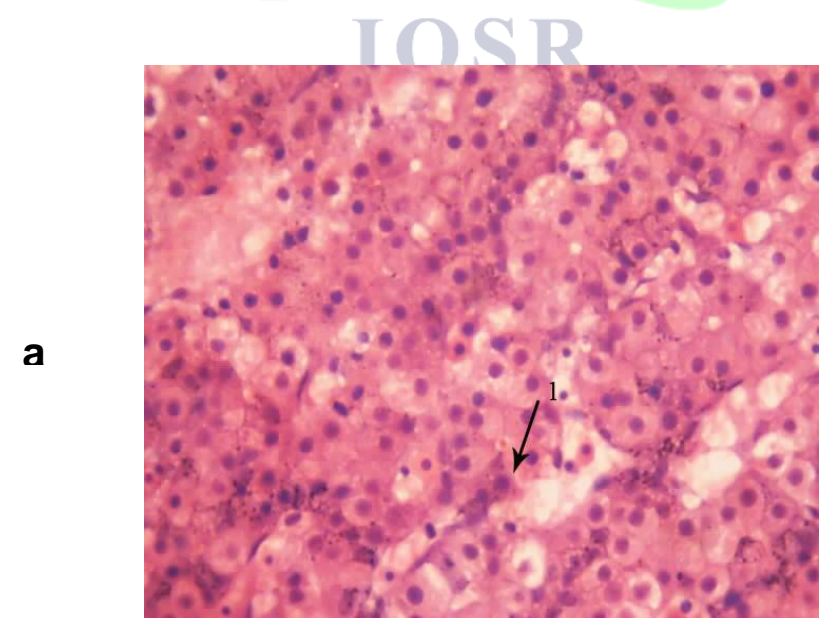

Fig. 2. Control liver (1 $\rightarrow$ a. Normal hepatocyte with clear nucleus) (H \&E- 40x) 


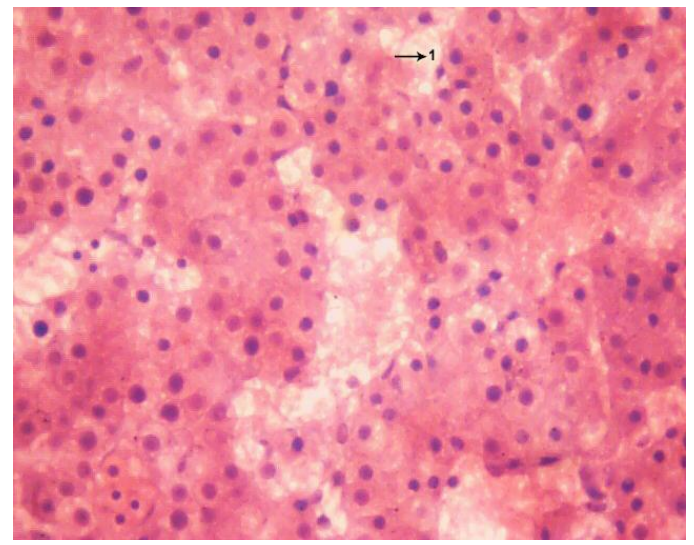

Fig. 3. $0.1 \mathrm{mg}$ Acrylamide $(24 \mathrm{hr})$ treated $(\mathrm{H} \& \mathrm{E}-40 \mathrm{x})(1 \rightarrow$ sinusoidal spaces $)$

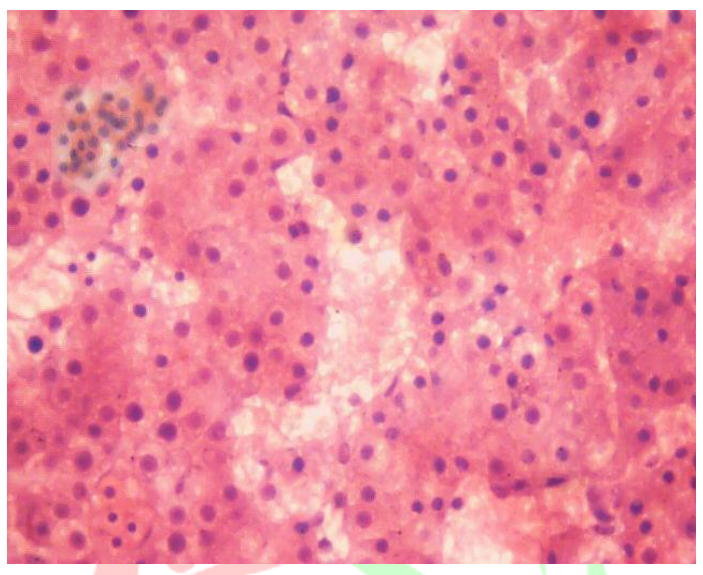

Fig. 4. $0.1 \mathrm{mg}$ Acrylamide (48 hr) treated (H \&E- 40x)

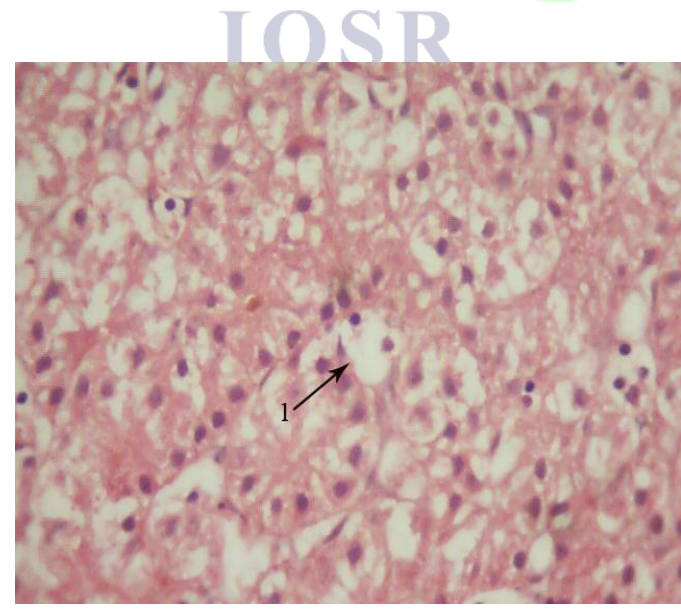

Fig. 5. $0.1 \mathrm{mg}$ Acrylamide $(72 \mathrm{hr})$ treated $(\mathrm{H} \& \mathrm{E}-40 \mathrm{x})(1 \rightarrow$ vacuolating changes in sinusoidal spaces) 


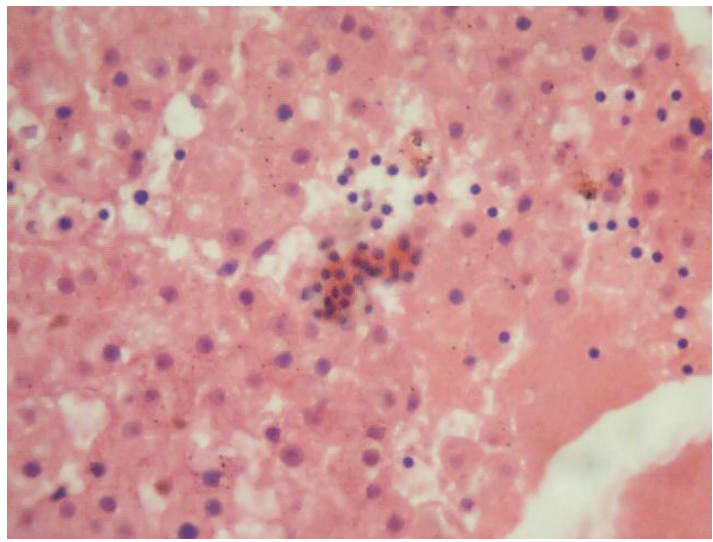

Fig. 6. $0.2 \mathrm{mg}$ Acrylamide ( $24 \mathrm{hr})$ treated (H \&E- 40x)

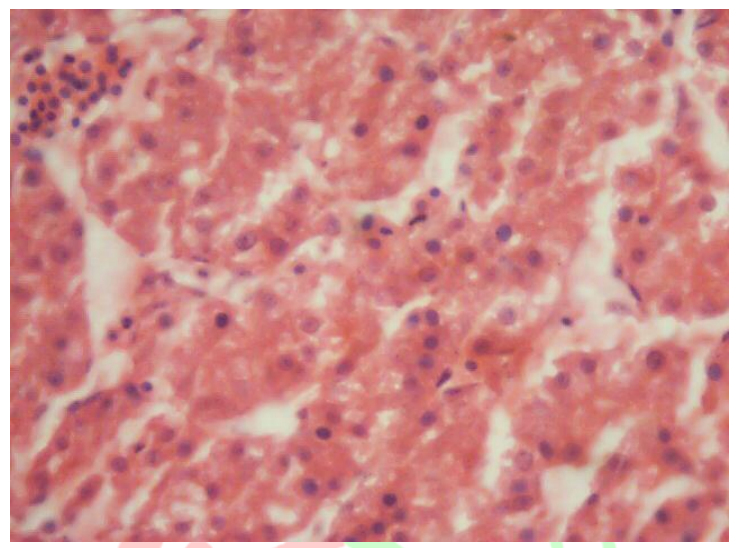

Fig. 7. $0.2 \mathrm{mg}$ Acrylamide (48 hr) treated (H \&E- 40x)

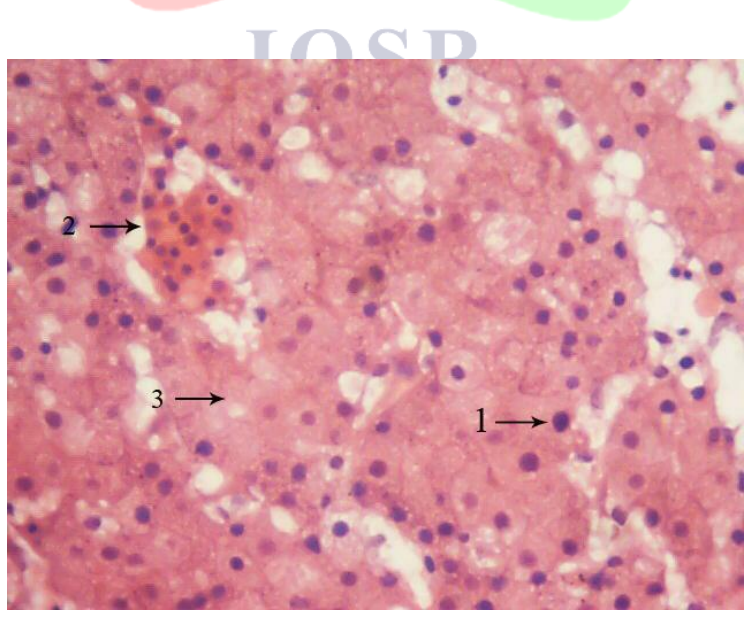

Fig. 8. $0.2 \mathrm{mg}$ Acrylamide ( $72 \mathrm{hr}$ ) treated (H \&E- 40x) ( $1 \rightarrow$ pycnotic nuclei, $2 \rightarrow$ hemorrhages, $3 \rightarrow$ necrotic changes) 


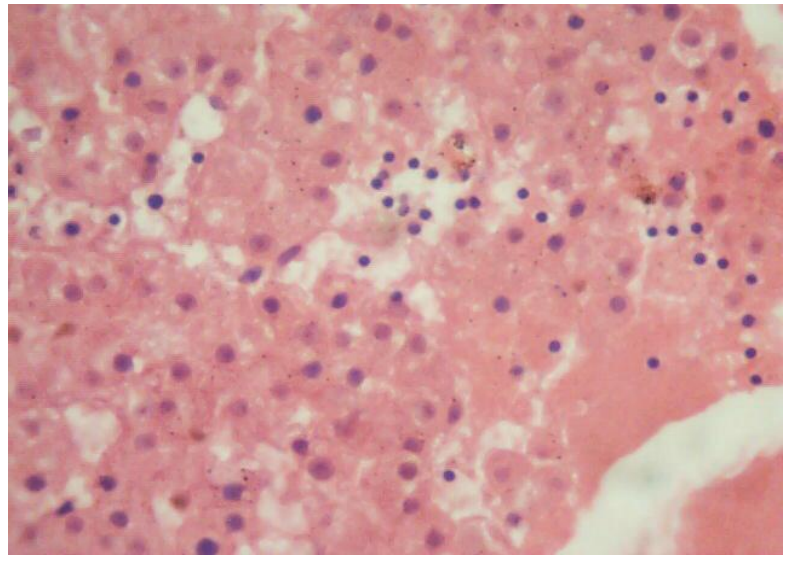

Fig. 9. 0.3mg Acrylamide (24 hr) treated (H \&E- 40x)

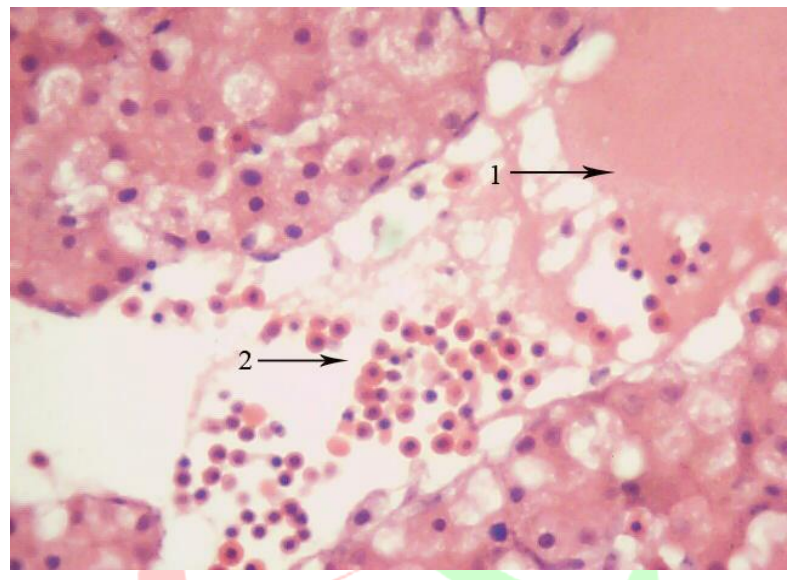

Fig. 10. $0.3 \mathrm{mg}$ Acrylamide $(72 \mathrm{hr})$ treated $(\mathrm{H} \& \mathrm{E}-40 \mathrm{x})(1 \rightarrow$ complete loss of architectural details of hepatocytes, $2 \rightarrow$ infiltrations)

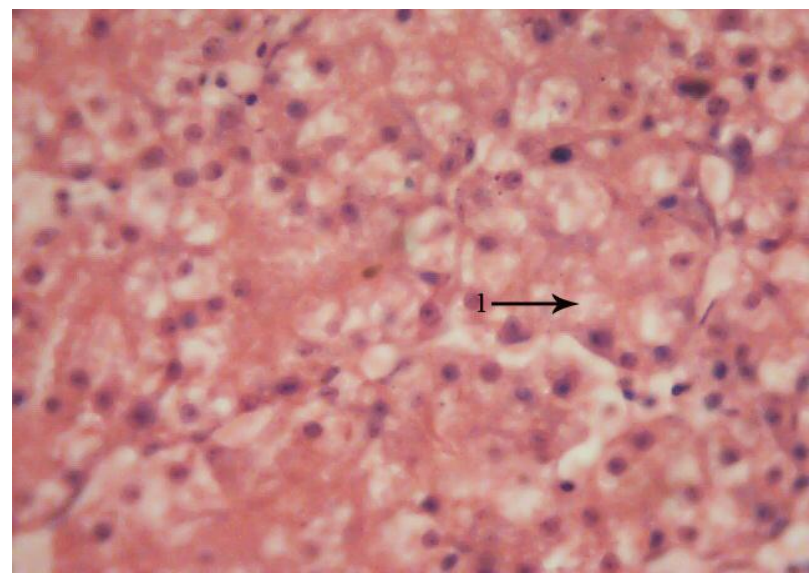

Fig. 11. $0.01 \mathrm{mg}$ Cadmium chloride $(72 \mathrm{hr})$ treated $(\mathrm{H} \& \mathrm{E}-40 \mathrm{x})(1 \rightarrow$ vacuolations in sinusoidal spaces) 


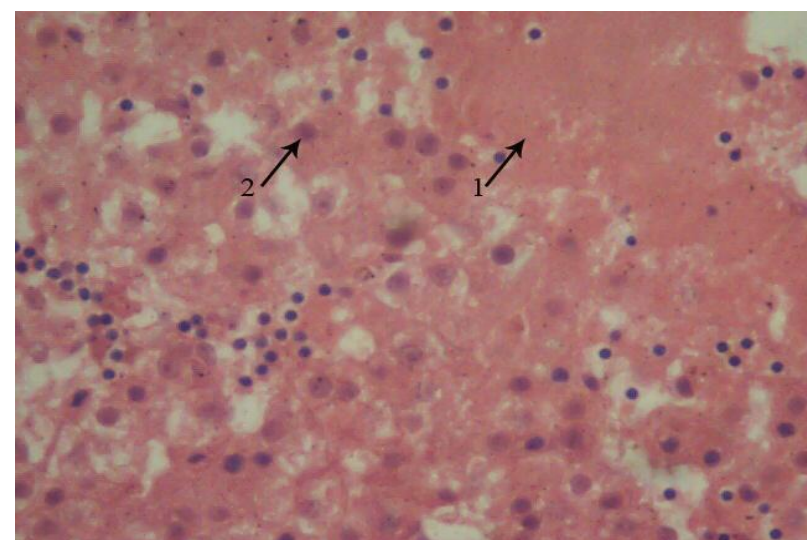

Fig. 12. $0.03 \mathrm{mg}$ Cadmium chloride ( $48 \mathrm{hr})$ treated $(\mathrm{H} \& \mathrm{E}-40 \mathrm{x})(1 \rightarrow$ necrotic changes, $2 \rightarrow$ pycnotic nuclei)

\section{Discussion}

Chick embryos have been used in the past for several years to investigate the effect of environmental chemicals and radiations on developmental effects, morphogenesis, etc. Liver is the major metabolizing organ which detoxifies a number of drugs and xenobiotics. The current study on genotoxicity of acrylamide and cadmium chloride in chick embryonic system using micronucleus test as an end point reveals that there is a significant induction of $\mathrm{MN}$-Es in $\mathrm{AC}$ and $\mathrm{CdCl}_{2} \mathrm{treated}$ animals and it is dose and time dependent. The MN-test in chick embryo gave clearly positive and dose-dependent results for acrylamide and cadmium chloride, which are both well-characterized but weak mutagens. There was a dose and time dependent increase in the induction of $\mathrm{MN}$ in peripheral blood erythrocytes in chick embryos treated with $\mathrm{CdCl}_{2}$. Cadmium is non-mutagenic in bacterial tests and only weak mutagenic in mammalian cells in vitro. Inhibition of DNA repair has been identified as a critical mechanism contributing to the genotoxic potential of cadmium. The MNT in chick embryo is a reliable alternative genotoxicity assay system, which is physiologically closer to in vivo conditions than conventional in vitro genotoxicity tests, not conflicting with ethical aspects or regulatory issues of animal protection.

In the present investigation the Acrylamide and Cadmium chloride treatment to chick embryo induced several pathological changes in the liver like, pycnotic nuclei, hemorrhages, fatty infiltrations, necrosis, pushing of nucleus to the periphery, sinusoidal dilations etc depending upon dose and duration of incubation of compound in liver hepatocytes.

Nagao et al., 2007 \& Vasundhara in 2005 [14,15], reported that Acrylamide treatment in the liver of rats showed frequent necrosis and bleeding, indicating hypertrophy of nuclei, pycnotic nuclei, proliferation of sinusoidal bile ducts and hemorrhages. Fatty infiltration in liver of rabbits on administration of Cadmium was reported by Subramanyam et al., 1992 [16]. Extensive histopathological lesions like hepatocytic enlargements, necrosis and fatty changes were observed in rat and mice by Koller, 2001 [17] in Cadmium administration. From the present study it is clear that Acrylamide and Cadmium chloride caused mild to severe hepatic changes in $11^{\text {th }}$ day old chick embryonic liver.

\section{Conclusion}

In conclusion the metal ion, $\mathrm{Cd}$, had severe damaging effect on chick embryonic liver than $\mathrm{AC}$ and however our study has revealed that these two are causing damage to the embryos. Therefore our study, based on two environment associated compounds, Acrylamide of plastics, and cadmium of industrial wastes, suggests that exposure of embryonic systems including pregnant are necessary to avoid to get damage from these chemicals at the time of embryonic growth.

\section{Acknowledgments}

We thank University Grants Commission and DRDO New Delhi, for providing financial support to carry out our research work. Department of Biochemistry of Sri Venkateswara University is financially supported by DST-FIST and UGC BSR, New Delhi.

\section{References:}

1. K. Jayanth Rao, Effect of systemic pesticide phosphomidon on some aspects of metabolism in fresh water fish Tilapia Mossambica (peters), Ph.D. Thesis, S.V University, Tirupati. 
2. International Agency for Research on cancer IARC (1994) Monographs on the evolution of Carcinogenic Risks to Humans, some industrial chemicals, IARC Scientific publications, Lyon, France 60:389-433.

3. C.J. Summer, T.R. Fennet, T.A. Moore, B. Chanas, F. Gonzales, B.I. Ghanayem, Role of cytochrome p450 2EI in the metabolism of acrylamide and acrylonitrile in mice, Chem. Res.Toxicol, 12, 1999, 1110-1116.

4. D.M. Lapadula, M. Bowe, C.D. Carrington, L. Dulak, M. Friedman, M.B. Abou-Donia, In vitro binding of $\mathrm{C}^{14}$ acrylamide to neurofilament and microtubule proteins of rats, Brain Res 481, 1989, 157-161.

5. G.A. Sega, R.P. Valdivia Alcota, C.P. Tancongco, P.A. Brimer, Acrylamide binding to the DNA and protamine of spermiogenic stages in the mouse and its relationship to genetic damage, Mutat. Res 216, 1989, 221-230.

6. A. Besaratinia, GP. Pfeifer, Weak yet distinct mutagenicity of acrylamide in mammalian cells, $J$ Natl cancer institute 95, 2003, 889-896.

7. M.A. EI-Hady, H.S. EI-Sabbagh, Transplacental transfer of cadmium and its toxic effect on the embryo-fetal development in rats: Proc. $3^{\text {rd }}$ congress on toxicology Dev., Count., Cairo, Egypt Vol.II 19-23:309-316.

8. International Agency for Research on cancer (1993) Beryllium, cadmium, mercury \& Exposures in the Glass Manufactruring Industry. In Monographs on the Evolution of Carcinogenic Risks to Humans; IARC : Lyon, France, Volume 58, pp. 119-236.

9. National Toxicology Program (2000) Ninth report on carcinogens. National Toxicology Program, Research Triangle Park, NC, USA.

10. U. Glaser, D. Hochrainer, F.J. Otto, H. Oldiges, Carcinogenicity and toxicity of four cadmium compounds inhaled by rats, Toxicol. Environ. Chem 27, 1990, 153-162.

11. S. Takenaka, H. Oldiges, H. Konig, D. Hochrainer, G. Oberdorster, Carcinogenicity of cadmium chloride aerosols in wistar rats, J.Natl. Cancer Inst 70, 1983, 367-373.

12. M.P. Waalkes., S. Rehm, M.G. Cherian, Repeated cadmium exposures enhance the malignant progression of ensuing tumors in rats, Toxicol. Sci 54, 2000,110-120.

13. G.L. Humason, Animal tissue techniques- $3^{\text {rd }}$ Ed (Co. San Fransisco: W.H. Freeman, 1972).

14. Nagao Totani Mino Yawata, Yuko Ojiri, Yoshio fuzioka, Effects of trace acrylamide intake in wistar rats, J.Oleo Sci 56(9), 2007, 501-506.

15. K. Vasundhara, Characterization of rat glutathione S-transferases under the influence of methyl cholanthrene, Ph.D thesis, S.V.University, Tirupati, India, 2005.

16. G. Subramanyam, M. Bhaskar, S. Govindappa, The role of cadmium in induction of atherosclerosis in rabbits, Indian Heart J 44(3), 1992, 177-180.

17. L.D. Koller, B.V. Stang, M.P. de la Paz, M.V. Ruiz Mendez, Pathology of "toxic oils" and selected metals in the MRL/lpr mouse, Toxic pathol 29 (6), 2001, 630-638. 